\title{
Research on Structure and Application Strategy of Ecological Practice Teaching System for Teacher Education Major in Local Colleges and Universities
}

\author{
JiSheng He and JiaMing Zhong ${ }^{*}$ \\ XiangNan University, Chenzhou, Hunan, China \\ *Corresponding author,email:jmzhongcn@163.com
}

\begin{abstract}
Keywords: Local Colleges and Universities; Teacher Education Major; Ecological Practice Teaching System; Strategy
\end{abstract}

\begin{abstract}
The segment of practice teaching in teacher education major has been weakened by most local colleges and universities. To cultivate application-oriented primary and secondary school teacher, it is quite urgent for local colleges and universities to enhance practice teaching for their teacher education major and to effectively improve teaching practical ability for their students majoring in teacher education. Effective strategies mainly include increasing teaching hours and credits for practice teaching, establishing scientific and rational practice teaching system, stressing reform on course teaching methods for teacher education major, enhancing teaching practice base construction, stressing educational probation and practice and coordinating graduation thesis with education practice; etc.
\end{abstract}

\section{Introduction}

Teacher education major is a major that highly emphasizes on practice. Its close relation to practice determines the importance to combine teaching theory with practice for teaching education major. However, after most universities, originally Normal Universities were upgraded into comprehensive university, the special characteristics of teaching education have been weakened to some extent and teaching education major has been gradually marginalized. The segment of practice teaching in teacher education major is weakened, which is mainly indicated by one-sided pursuit of comprehensive and systematic teaching knowledge and high emphasis on theory teaching, especially on basic theory teaching. Its application and practice are ignored, and proportion on practice teaching such as practice and probation is obviously insufficient. Practice teaching becomes merely a formality. This serious issue is not conducive to the cultivation of teaching practice ability for students majoring in teacher education. Talents trained are in serious disjunction with social demand and they cannot meet the needs of teacher in the new era of social development. Therefore, in order to cultivate application-oriented primary and secondary school teacher, it is urgent to explore practice teaching mode for teacher education major in local colleges and universities and to enhance their practice teaching proportion. It will help effectively improve teaching practical ability for students majoring in teacher education and cultivate education-applied talents which actually meet times' demand.

\section{The Indications for Practice Teaching of Teacher Education Major Getting Weakened in Local Colleges and Universities}

Low Status for Teacher Education Courses. The status of teacher education courses is low because it is not highly considered in local colleges and universities. Its professional course is usually opened as general public course and taught in big classes. The number of students is at least eighty, sometimes even one hundred and fifty. Because there are too many students, it is not conducive to improve teaching quality for education theory class, nor is it conducive to organize practice teaching.

Low Proportion of Practice Classes and Insufficient Training on Teaching Skills. The teachers' professional knowledge mainly consists of three aspects: One is subject-matter knowledge, 
which is knowledge of the subject that teachers teach. The second is conditional knowledge, which is knowledge related to teacher education that teachers have. The last is practical knowledge, which is teaching experience that teachers accumulate [1]. Course teaching in teacher education major does not emphasize on teaching of practical knowledge for a long time. They emphasizes more on theory than practice, more on teaching than training and more on teaching than learning. Therefore, students lack teaching experience and tacit knowledge. Besides, they lack necessary training on teaching skills before education probation. Currently students majoring in teacher education in local colleges and universities are arranged to do trial teaching for only one week before education probation. Students will have to prepare lesson plans and do trial teaching. There is so little time that only one or two lessons can be listened to by instructor for each student. Therefore, it is quite difficult for instructor and student to find out shortcomings, and their teaching ability cannot be improved.

Short Time and Single Pattern of Education Practice and Probation and Ignorance on Guidance of Reflective Thinking Courses. Education practice and probation are the important way and also the key parts to develop teaching practical ability for students majoring in teacher education. The acquisition of practical experience is an important prerequisite for teachers' professional development. It is highly valued in foreign countries. For example, the proportion of education practice is twenty percent in US. The period of education practice and probation in UK is at least twenty weeks. The probation period of probation for students majoring in medicine lasts for one year in China, while only around eight weeks for graduates majoring in teacher education. It only covers four percent of all learning hours.[2] Students can only teach five to six lessons in the probation period, and sometimes even fewer lessons. Current form of education probation is mainly imitative practice. It neglects the cultivation of reflective thinking behavior for students majoring in teacher education, etc.

\section{Research on Structure and Application Strategy of Ecological Practice Teaching System for Teacher Education Major in Local Colleges and Universities}

To enhance practice teaching for teacher education major in local colleges and universities, the first priority is to enhance emphasis on practice teaching from all aspects such as plans for talents cultivation in teacher education major, layouts for course system, teaching materials selection, and practice teaching facility as well as construction of practice base. It will create a preferable condition for practice teaching. The second is to explore practice teaching patterns for teacher education major in local colleges and universities, and also to adopt effective strategies for practice teaching.

Increases Proportion of Practice Teaching Hours and Credits and Establishment of Scientific and Rational Practice Teaching System. (1) Further revise and improve talents cultivation plan for teacher education major and establish rational course structure system for teacher education major: Increase proportion of practice teaching hours and credits and make practice in subject teaching courses cover more than fifty percent and twenty-five percent for courses such as education, psychology and modern education technology. Emphasize teaching skills training before education probation and increase training period to two weeks. Set up strict standard for trial teaching of interns; (2) Make reforms on courses teaching contents for teacher education major and highlight practice teaching content: One is to consolidate basic knowledge of teaching theory, to establish comprehensive frame and system for education theory knowledge, to make teaching content simple and concise with case examples, to emphasize on combination between theory and practice, and to timely implement new education theory knowledge. The second is to enhance skills training for education teaching major and to cultivate education teaching skills and abilities for students majoring in teacher education by combining skills training with education theory knowledge. For example, introduce skills for new courses, blackboard design, course finalization, development and application of course resources and courseware making, etc. The third is to enhance practical ability for education teaching, which includes not only the ability to analyze education practice issues by flexible use of education theory knowledge, such as ability of course design, teaching organization, 
teaching method application, teaching routine consistence, education technology application, case analysis and evaluation and reflection on course teaching, but also teaching intelligence and teaching deployment. The fourth is to stress on research ability and content of education teaching, etc; (3) Make reforms on cultivation pattern and proactively explore "Three plus One" cultivation pattern for teachers: "Three plus One" pattern means three years" professional education on subject and one year's professional education on teaching. This pattern separates subject education from teaching education and increases option opportunity for students majoring in teacher education. Also it makes students majoring in teacher education have more time for professional education of teaching, which will enhance practice teaching. To achieve this, it is important to make reforms on course content of teacher education and to enhance basic knowledge, to update content and to expand knowledge when setting up course plans, especially to emphasizes more on links with practice on primary and secondary school education teaching.

\section{Emphasize on Reforms on Course Teaching Method for Teacher Education Major. To} enhance practical value of course teaching for teacher education major, it is important to emphasize more on reforms on course teaching method for teacher education major and introduce various teaching methods, thus to cultivate teaching practical ability of students for teacher education major.

(1) Emphasize on life-relevance and modernization of teaching: During teaching, teachers should make reforms from practical education and basic education courses and find out accurate combination between theory and practice. Except for this, they should also clarify basic concepts, preve3nt derivation and explanation of complicated abstract nouns, make detailed research on teaching materials and fully understand spiritual essence and connotation of concepts, theory and principles as well as its instruction value for education practice. Moreover, they should highlight difficult points and important points, grasp doubtful points, instruct students to read more related materials by combining lessons. These materials include education books, newspaper and journals. It will help expand students' knowledge and horizon and better understand actual teaching for primary and secondary schools. It will also help enhance teaching effect of teacher education related courses. Teachers should adopt modern teaching methods for teaching.

(2) Adopt case examples for teaching: Try to teach basic theory by combining actual teaching in primary and secondary schools and offer case examples in primary and secondary schools to encourage analysis and discussion for students. These cases include typical cases about psychological problems for primary and secondary students and typical courses that in-service teachers are teaching, etc. Further understand basic theory knowledge on subjects for teacher education major. Apply education of various subjects to courses in primary and secondary schools.

(3) Apply Teacher-Student Interaction teaching method: Teacher-Student Interaction teaching method is an important strategy to enhance practical teaching for teacher education major and to promote development of practical ability for students majoring in teacher education. This method is to adopt theory of role switch. Under teacher's instruction, students play role of teachers and teach on the platform. Switch from learning to teaching and learn from teaching. Combine teaching with learning. Specifically speaking, taking the current teaching material as basic carrier, following teachers' instruction and taking students' independent learning and cooperative discussion as basis, students pretend to be teachers, stand on the platform and give lessons on teaching content at the spare time. The teaching content is the content either teacher designate or students select. Organize students to take participation in activities such as independent learning, group discussion, lessons writing, courses teaching and class discussion. It will help enrich students' own professional knowledge, improve professional skills, enhance professional merits and promote profession as a teacher [3].

(4) Apply Micro Teaching Method: Organize students for teaching simulation practice in a very small classroom. It will help provide students with timely, straight, vivid and comprehensive feedback and stimulate their initiatives to train, and then effect of practical training will be enhanced.

(5) Combine practice in class with practice teaching after class: Practice in class includes 
listening to lessons taught by specialists, watching teaching videos, simulating teaching and doing work by pretending to be class director as well as adopting the way to analyze and simulate teaching based on teaching videos. Practice teaching after class includes education teaching probation in primary and secondary schools. To enhance practice teaching after class, it is important to cooperate with primary and secondary schools and provide more practice opportunities such as post practice and extracurricular activities instruction for students majoring in teacher education.

Emphasis on construction of education practice base and on education practice and probation. (1) Enhance construction of education practice base: During the process of application-oriented talents cultivation, practice teaching is the key. It needs strong conditional support. Therefore, it is important to enhance construction of basic teaching hardware facilities for probation schools, to improve its office and life conditions, to establish shared platforms for practice base and practice teaching and to cultivate students by practice. It is also important to establish practice base for primary and secondary schools, to promote consistent innovation of teaching and learning, to take the best advantage of teaching research in graduate colleges and to provide intellectual support for base schools. It is important to enhance interaction with basic education, to open cooperation and research opportunities on teaching research and teaching reform projects for base schools and to present research results of teachers from base schools, as well as to establish joint talents cultivation systems which can share resources, talents and management, etc.

(2) Emphasis on Education Practice and Probation Reforms and Introduction of Reflective Training: (a) Postpone education practice and probation time: Make education practice and probation time around six to seven percent of all class hours. Postponing education practice and probation time will help students enter into the role more quickly and reduce their adaptation time; (b) Break the rule of one-time practice and probation when arranging education practice and probation: It will help penetrate education practice and probation into the whole process of teacher education. Launch practice and probation with special subjects, Assign specific tasks and purposes for each practice and probation to ensure its continuity and periodicity. Ensure that students have sufficient time to understand education teaching in primary and secondary schools. It will help enrich their perpetual knowledge and enhance cultivation of their subjective consciousness and role consciousness; (c) Instruct students to do reflective thinking on education practice: Divide education practice and probation process into several stages. Provide students with time guarantee for reflective thinking by the process of practice, thinking, re-practice and re-thinking. Do reflective thinking through conversation and communication, which is to making formal conversation or casual conversation between instructors and interns. Do reflective thinking through watching teaching videos, which is to make interns do reflective thinking by video, and then instructors discuss this method with interns to improve its effectiveness. Do reflective thinking by studying case examples, which is to do reflective thinking on typical cases and to adopt different methods such as on-site teaching, watching videos, group discussions, mutual communication, role playing, interview, forum and debate, and also to adopt different strategies such as watching, listening, touching and expressing. It will help interns think, exam and communicate from all aspects and improve teaching method [4].

Emphasis on Coordination between Educational Probation and Practice and Graduate Thesis. Graduate thesis and education probation is the last practice for students in four years' college and university life. At this stage, students have completed all theory courses and professional courses and finished training for several practice tasks. They have practice experience. When this stage is implemented, many colleges and universities will ask students to do internship for some time, students will come back to college for graduate thesis after internship is completed. While some colleges and universities will ask students to complete graduate thesis, then ask them to do internship after thesis. It is proved that neither of these two ways can achieve good results. We think that it will bring better effects to combine education probation with graduate thesis. The specific way is: in the second semester of junior year, colleges release graduate thesis subject, and then arrange internship at a proper time. It will help students do their internship with their doubts and questions and complete tasks during internship, and also complete their thesis during internship. 
This will make graduate thesis more close to education practice, more real and practical as well as more easy to be implemented.

Moreover, launch various education practice activities, such as education investigation and teaching skill contest. Take participation in summer camp or winter camp for primary and secondary schools. Encourage students to be tutors or do part-time teachers in social training centers, etc. All these are effective strategies to enhance practice teaching for teacher education major and to cultivate application-oriented teachers for primary and secondary schools.

\section{Acknowledgements}

The research has been sponsored by teaching reform and research project of regular institutes of higher education in Hunan Province in 2016. The project is named as Research and Practice on Cultivation Strategy of Application-oriented Teachers in Primary and Secondary Schools. ( XiangJiaoTong[2016]No.400-738), scientific research project in Xiangnan university in 2016 "the application technology of chenzhou education development countermeasure research (2016xj26)

\section{References}

[1] Y.L. Qin: Modern Pedagogy(Sichuan Education Press, China 2008).

[2] X.D. Guo: Journal of Hubei Three Gorges College, (2000) No.6.

[3] J.H. He: Modern Education Science, High Education Research, (2008) No.4.

[4] Z.H.Wu, H.M. Liu: Teacher Education Research, (2004) No.5.

[5] G.M. Zhang,H. Xu: Journal of Yangtze University(Social Sciences),Vol. 37 ,2014) No. 4,p.132-135.

[6] Q.X. Zhang,H.C.Wang and J. Su: Modern educational science,(2015),p.96-98.

[7] L. Ye: Teachers role and development of new agents (Education Science Press, China 2001).

[8] Ernest boyer L.: Speech on education reform in America ( Science Education Publishing House, China 2003). 